\title{
Elution of Alkaloids from Cation Exchangers
}

\author{
A. BERGGREN, C. O. B JöRLING and B. WILLMAN-JOHNSON \\ Research Laboratories of Pharmacia Ltd., Uppsala, Sweden
}

\begin{abstract}
Elution of tertiary and quaternary amines of a high molecular weight from a strong cation exchanger can be performed with $1 \mathrm{~N}$ hydrochloric acid if a resin with a very low degree of crosslinking is used. Usually alcohol will considerably improve the elution rate and for some compounds is in fact necessary.
\end{abstract}

0 rganic cations of high molecular weight, e.g. alkaloidal ions, can usually be adsorbed on strong cation exchange resins. However, once the amines are adsorbed they are often difficult to elute. Bregman ${ }^{1}$ states that molecular adsorption is negligible for all univalent organic cations for Dowex 50, all active sites of the exchanger thus being available.

For organic bases the situation is more complicated. Some authors have been able to elute tertiary alkaloidal ions with alcoholic ammonia and Büchi and Furrer ${ }^{2}$ also tried aqueous $10 \%$ hydrochloric acid for the elution of quinine but very large eluates were necessary. The difficulties of the elution can be avoided by using an inorganic ion exchanger, e.g. Decalso, as suggested by the present authors ${ }^{3}$. Although this method gives good results it is somewhat inconvenient because of the low capacity.

When working on resins with cations of high molecular weight the importance of the degree of crosslinking has been emphasized by Moore and Stein ${ }^{4}$, Davey $^{5}$, Balenović and Stefanac ${ }^{6}$, Jacobs, Work and Kressman ${ }^{7}$, Büchi and Furrer ${ }^{2}$, van Etten ${ }^{8}$, Kunin and Myers ${ }^{9}$, Sjöström and Nykänen ${ }^{10}$ and Hale, Packham and Pepper ${ }^{11}$. Briefly it may be stated that with a low degree of crosslinking the resin swells to a higher extent and becomes more porous. This causes the resin to take up and give off big ions more easily.

Most experiments performed on ions of moderate size have been restricted to aqueous solutions but with bigger ions it would seem necessary to modify the solvent. Bodamer and Kunin ${ }^{12}$ have shown that ion-exchange in nonaqueous media is possible although the rate of the exchange is lower than in water. The main condition is that the resin swells to such an extent that the pores can hold the ions. Gemant ${ }^{13}$ investigated ion exchange in hydrocarbons and Drèze and Reith ${ }^{14}$ used $20 \%$ alcohol as a solvent. Rückert and Samuelson ${ }^{15}$ studied the influence of alcohol on the shrinkage and showed that more glucose is adsorbed from alcohol than from water. Sjöström and Nykänen ${ }^{10}$ used alcoholic media at the elution from anion exchangers.

Acta Chem. Scand. 12 (1958) No. 7 
Table 1. Compounds eluted with $1 \mathrm{~N}$ hydrochloric acid in $25 \mathrm{ml}$ eluate.

Per cent recovery for varying strengths of alcohol

\begin{tabular}{|c|c|c|c|c|c|c|c|c|c|c|c|c|c|c|c|c|}
\hline \multirow{2}{*}{ Compound } & \multirow{2}{*}{$\begin{array}{l}\text { Per cent } \\
\text { alcohol } \\
\text { Eluate }\end{array}$} & \multicolumn{3}{|c|}{0} & \multicolumn{3}{|c|}{30} & \multicolumn{3}{|c|}{50} & \multicolumn{3}{|c|}{70} & \multicolumn{3}{|c|}{90} \\
\hline & & 1st & $2 n d$ & sum & lst & 2nd & sum & lst & 2nd & sum & lst & $2 \mathrm{nd}$ & sum & 1st & 2nd & sum \\
\hline \multirow{8}{*}{\multicolumn{2}{|c|}{$\begin{array}{l}\text { Papaverine ethylto- } \\
\text { sylate } \\
\text { Ethyl quinolinium } \\
\text { bromide } \\
\text { Hyoscine methyl- } \\
\text { nitrate }\end{array}$}} & & & & & & & 100.5 & & 100.5 & & & & 102.7 & & 102.7 \\
\hline & & 0 & 0 & 0 & & & & 99.9 & & 99.9 & & & & & & \\
\hline & & & & & & & & & & & 99.7 & 0.6 & 100.3 & & & \\
\hline & & 95.5 & 4.5 & 100.0 & & & & & & & 101.4 & 0.0 & 101.4 & & & \\
\hline & & 98.6 & & 98.6 & & & & & & & & & & & & \\
\hline & & $\begin{array}{r}98.6 \\
919\end{array}$ & & 98.6 & & & & & & & & & & & & \\
\hline & & 101.8 & & 101.8 & & & & & & & & & & & & \\
\hline & & 104.3 & & 104.3 & & & & & & & & & & & & \\
\hline \multirow{3}{*}{\multicolumn{2}{|c|}{$\begin{array}{l}\text { Oxaditon / } 1 \\
\text { Quinine ethiodide }\end{array}$}} & 99.6 & & 99.6 & & & & & & & 103.1 & & 103.1 & & & \\
\hline & & & & & & & & & & & 99.3 & 0.0 & 99.3 & & & \\
\hline & & 20 & 20 & 40 & & & & & & & 98.7 & 0.0 & 98.7 & & & \\
\hline \multirow{2}{*}{\multicolumn{2}{|c|}{ Codeine ethiodicie }} & 85.5 & 11.3 & 96.8 & & & & 95.4 & 1.9 & 97.3 & 100.7 & 0.0 & 100.7 & & & \\
\hline & & 97.8 & 2.4 & 100.2 & & & & 98.3 & 2.3 & 100.6 & 100.7 & 1.5 & 102.2 & & & \\
\hline \multirow{2}{*}{\multicolumn{2}{|c|}{ Berberine sulphate }} & & & & & & & & & & 100.0 & 0.0 & 100.0 & & & \\
\hline & & & & & & & & & & & 99.8 & 0.0 & 99.8 & & & \\
\hline \multirow{2}{*}{\multicolumn{2}{|c|}{ Strychnine ethiodide }} & 69.3 & 22.5 & 91.8 & & & & & & & 99.2 & 0.0 & 99.2 & 98.3 & & 98.3 \\
\hline & & 59.2 & 30.4 & 89.6 & & & & & & & 99.6 & 0.0 & 99.6 & 98.1 & & 98.1 \\
\hline \multirow{3}{*}{\multicolumn{2}{|c|}{$\begin{array}{l}\text { Benzethonium } \\
\text { chloride }^{2} \\
\text { DMABF }^{2}\end{array}$}} & 0 & & 0 & & & & & & & 99.6 & 1.7 & 101.3 & 99.9 & 0 & 99.9 \\
\hline & & & & & & & & & & & 97.2 & 1.7 & 98.9 & 99.3 & 0.9 & 100.2 \\
\hline & & 0 & 0 & $\begin{array}{c}0 \\
\operatorname{at} 80^{\circ}\end{array}$ & 11.5 & $|20.3|$ & $\begin{array}{l}31.8 \\
3\end{array}$ & $\begin{array}{l}91.0 \\
92.9\end{array}$ & $\begin{array}{l}7.6 \\
5.3\end{array}$ & $\begin{array}{l}98.6 \\
98.2\end{array}$ & $\begin{array}{l}99.2 \\
99.2\end{array}$ & $\begin{array}{l}1.2 \\
0.9\end{array}$ & $\begin{array}{l}100.4 \\
100.1\end{array}$ & 98.5 & 3.2 & 101.7 \\
\hline
\end{tabular}

$1 \mathrm{~N}, \mathrm{~N}, \mathrm{~N}, \mathrm{~N}^{1}$-tetraethyl- $\mathrm{N}^{1}, \mathrm{~N}^{1}$-dimethyl-3-oxapentane-1,5-diammonium dimonohydrogen tartrate

${ }^{2}$ the elution was performed with $1 \mathrm{~N}$ sulphuric acid in $10 \mathrm{ml}$ eluate

3 the elution was performed with $2 \mathrm{~N}$ hydrochloric acid

Previously we ${ }^{16}$ have found that both tertiary and quaternary amines can easily be eluted with acids if $i$. the degree of crosslinking of the resin is low, $i i$. the solvent contains ethanol, methanol, or acetone in varying amounts.

It was found that 5-50 $\mu$ equiv. of the compounds investigated were quantitatively retained by Dowex $50 \mathrm{X1}$ in a column $20-30 \times 4 \mathrm{~mm}$ and could not be eluted by the usual solvents. In Table 1 the elution of different substances has been made with $1 \mathrm{~N}$ hydrochloric acid in water or alcohol of different strengths. Although some compounds may be eluted with aqueous acid this medium is without effect for papaverine ethyltosylate, benzethonium chloride and DMABF [9-(4-dimethylamino-benzylidene)-fluorene ethyltosylate]. If the acid is made alcoholic its elution capacity is increased. $50-70 \%$ of alcohol seems to be sufficient and generally $15-20 \mathrm{ml}$ eluates gave quantitative recoveries. By taking small eluates of $5 \mathrm{ml}$ this phenomenon can be demonstrated and some typical curves are shown in Fig. 1 and 2. The effect of alcohol is not correlated to the molecular weight of the substance. It is interesting to note that DMABF which is soluble in hot water cannot be eluted by aqueous hydrochloric acid even at $80^{\circ}$. 


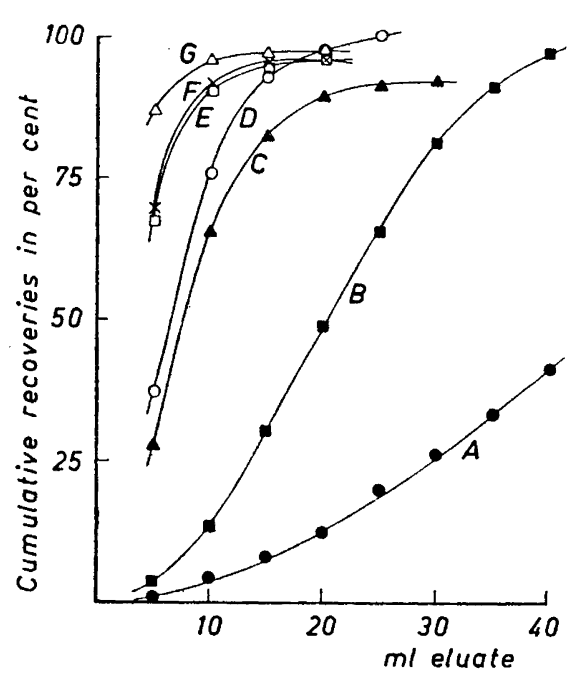

Fig. 1. Elution at different alcohol strengths with $1 \mathrm{~N}$ hydrochloric acid.

A Quinine ethiodide in water

B Strychnine ethiodide in water

C DMABF in $50 \%$ alcohol

D Quinine ethiodide in $70 \%$ alcohol

E DMABF in $70 \%$ alcohol

F DMABF in $90 \%$ alcohol

$\mathrm{G}$ Strychnine ethiodide in $70 \%$ alcohol

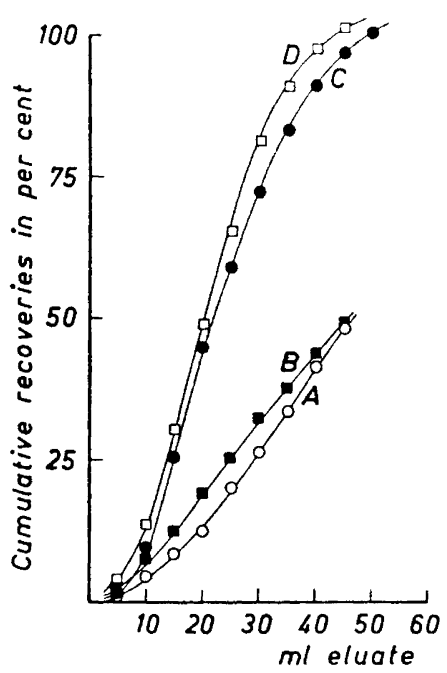

Fig. 2. Elution of tertiary amines and their corresponding quaternary compounds with $1 \mathrm{~N}$ hydrochloric acid in water.
A Quinine ethiodide
B Quinine sulphate
C Strychnine nitrate
D Strychnine ethiodide

From Fig. 2 may be seen that there is hardly any difference between the tertiary alkaloid and the corresponding quaternary compound in the two cases investigated. The elution curves were obtained with aqueous $1 \mathrm{~N}$ hydrochloric acid as alcoholic acids eluted both types of compounds too rapidly to obtain any reliable values.

Table 2. DMABF eluted with perchloric acid of different concentrations in alcohol of varying strengths.

\begin{tabular}{|c|c|c|c|c|c|c|c|c|c|c|c|c|}
\hline \multirow{3}{*}{$\begin{array}{c}\text { Acid } \\
\text { concentration }\end{array}$} & \multicolumn{12}{|c|}{ Per cent recovery for varying concentrations of perchloric acid } \\
\hline & \multicolumn{3}{|c|}{$0.2 \mathrm{~N}$} & \multicolumn{3}{|c|}{$0.5 \mathrm{~N}$} & \multicolumn{3}{|c|}{$1 \mathrm{~N}$} & \multicolumn{3}{|c|}{$2 \mathrm{~N}$} \\
\hline & lst & $2 \mathrm{nd}$ & sum & lst & 2nd & sum & lst & 2nd & $\sqrt{\text { sum }}$ & lst & 2nd & sum \\
\hline Alcohol \% 30 & 0 & 0 & 0 & 18.7 & 21.0 & 39.7 & 27.7 & 28.3 & 56.0 & 93.6 & 3.6 & 97.2 \\
\hline$\Rightarrow \quad " \quad 50$ & 82.0 & 14.8 & 96.8 & 96.8 & 2.0 & 98.8 & 98.6 & 0.9 & 99.5 & 92.9 & 7.1 & 1000 \\
\hline$" 70$ & 95.3 & 1.1 & 96.4 & 98.5 & 0 & & & 0 & 98.8 & 99.9 & 0 & \begin{tabular}{|l|}
99.9 \\
\end{tabular} \\
\hline$" 90$ & 9.5 .0 & 1.5 & 96.5 & 98.8 & 0 & 98.8 & 99.0 & 0 & 99.0 & & & \\
\hline
\end{tabular}

Acta Chem. Scand. 12 (1958) No. 7 
Table 3. The effect of the degree of crosslinking on adsorption and elution.

\begin{tabular}{|c|c|c|c|c|c|c|c|c|c|c|c|c|c|c|c|}
\hline \multirow{4}{*}{$\begin{array}{c}\text { Ton } \\
\text { exchanger }\end{array}$} & \multicolumn{15}{|c|}{ Per cent recovery } \\
\hline & \multicolumn{5}{|c|}{$\begin{array}{l}\text { Ethyl quinolinium bromide } \\
\text { Elution with } 1 \mathrm{~N} \text { hydro- } \\
\text { chloric acid in } 70 \% \text { alcohol } \\
\text { in } 25 \mathrm{ml} \text { eluate }\end{array}$} & \multicolumn{5}{|c|}{$\begin{array}{l}\text { Benzetonium chloride } \\
\text { Elution with } 1 \mathrm{~N} \\
\text { sulphuric acid in } 70 \% \\
\text { alcohol in } 10 \mathrm{ml} \text { eluate }\end{array}$} & \multicolumn{5}{|c|}{$\begin{array}{l}\text { DMABF } \\
\text { with } 1 \mathrm{~N} \text { hydro- } \\
\text { cid in } 70 \% \text { alcohol } \\
25 \mathrm{ml} \text { eluate }\end{array}$} \\
\hline & \multirow{2}{*}{$\begin{array}{l}\text { not } \\
\text { adsor- } \\
\text { bed }\end{array}$} & \multicolumn{4}{|c|}{ Eluate No. } & \multirow{2}{*}{$\begin{array}{l}\text { not } \\
\text { adsor- } \\
\text { bed }\end{array}$} & \multicolumn{3}{|c|}{ Eluate No. } & \multirow[b]{2}{*}{ Sum } & \multirow{2}{*}{$\begin{array}{l}\text { not } \\
\text { adsor- } \\
\text { bed }\end{array}$} & \multicolumn{4}{|c|}{ Eluate No. } \\
\hline & & 1 & 2 & 3 & Sum & & 1 & 2 & 3 & & & 1 & 2 & 3 & Sum \\
\hline \multirow[t]{2}{*}{$50 \mathrm{X1}$} & 0.0 & 99.7 & 0.6 & & 100.3 & 0.3 & 99.6 & 1.7 & & 101.6 & 0.0 & 99.2 & 0.9 & & 100.1 \\
\hline & & & & & & 0.0 & 97.2 & 1.7 & & 98.9 & 0.0 & 99.2 & 1.2 & & 100.4 \\
\hline \multirow[t]{2}{*}{$50 \times 2$} & 0.0 & 97.5 & 0.7 & 0.0 & 98.2 & 3.0 & 96.0 & 0.0 & & 99.0 & 0.0 & 87.8 & 8.4 & 0.7 & 96.9 \\
\hline & & & & & & 0.0 & 99.8 & 0.0 & & 99.8 & 0.0 & 85.7 & 11.4 & 1.7 & 98.8 \\
\hline \multirow[t]{2}{*}{$50 \times 4$} & 0.0 & 99.3 & 0.0 & 0.0 & 99.3 & 8.4 & 83.3 & 9.7 & 0.0 & 101.4 & 0.0 & 48.3 & 26.4 & 12.8 & 87.5 \\
\hline & & & & & & 0.0 & 95.2 & 4.9 & 0.0 & 100.1 & 0.0 & 52.6 & 24.2 & 11.5 & 88.3 \\
\hline \multirow[t]{2}{*}{$50 \times 8$} & 0.0 & 92.5 & 7.0 & 0.0 & 99.5 & 83.8 & 12.0 & 4.4 & 0.0 & 100.3 & 0.0 & 35.9 & 13.8 & 9.8 & 59.5 \\
\hline & & & & & & 59.9 & 22.4 & 11.0 & 5.2 & 98.5 & 0.0 & 45.5 & 12.5 & 8.1 & 66.4 \\
\hline \multirow[t]{2}{*}{$50 \times 12$} & 0.0 & 85.1 & 8.4 & 2.6 & 96.1 & 96.1 & 3.8 & 0.0 & & 99.8 & 0.0 & 64.1 & 12.6 & 5.2 & 81.9 \\
\hline & & & & & & 88.5 & 7.7 & 3.9 & 0.0 & 99.9 & 0.0 & 74.0 & 9.3 & 2.8 & 86.1 \\
\hline \multirow[t]{2}{*}{$50 \times 16$} & 0.0 & 79.0 & 12.2 & 6.3 & 97.5 & 95.1 & 5.0 & 0.0 & & 100.1 & 0.0 & 73.8 & 10.8 & 2.8 & 87.3 \\
\hline & & & & & & 86.7 & 10.0 & 2.6 & 0.0 & 99.3 & 0.0 & 66.6 & 11.4 & 4.8 & 82.8 \\
\hline
\end{tabular}

In Table 2 perchloric acid solutions of different concentrations and of various alcoholic strengths have been tested for their elution capacity towards DMABF. If the acid concentration is higher than $0.5 \mathrm{~N}$ and the alcohol strength more than $50 \%$ the elution is quantitative with $25 \mathrm{ml}$. Other experiments have shown that hydrochloric acid is somewhat inferior to perchloric acid and that sulphuric acid has a markedly lower elution power. As alcoholic solutions of perchloric acid are disagreable we have chosen $1 \mathrm{~N}$ hydrochloric acid as the general elutriant.

Substitution of ethanol for methanol or acetone gave for DMABF the same result. Thus, elution with $1 \mathrm{~N}$ hydrochloric acid in $70 \%$ methanol gave $100.6 \%$ recovery in $25 \mathrm{ml}$ eluate and in $70 \%$ acetone $100.3 \%$ recovery.

For a few compounds alcoholic potassium hydroxide is a good elutriant. Thus $0.5 \mathrm{~N}$ potassium hydroxide in 90 and $50 \%$ alcohol, respectively, gave quantitative recoveries of papaverine ethyltosylate in $25 \mathrm{ml}$ eluate. On the other hand 1.0 and $0.5 \mathrm{~N}$ potassium hydroxide in $70 \%$ alcohol gave only about $70 \%$ recoveries in $25 \mathrm{ml}$ eluate. As many compounds are unstable in alkaline medium and as column blanks are liable to become high these media were not further investigated.

Some experiments have been made with alcoholic solutions of sodium bromide, calcium chloride, barium bromide, and aluminium chloride. In $0.5 \mathrm{M}$ solutions in $50-70 \%$ alcohol the salts will elute DMABF but the elution is rather slow and seems generally to be inferior to that of hydrochloric acid.

In order to investigate the effect of crosslinking, cation exchangers from the same manufacturer with varying degrees of crosslinking were used in the same manner as before. Table 3 shows the results obtained on three different compounds. Of these molecules the ethyl quinolinium bromide is comparati- 


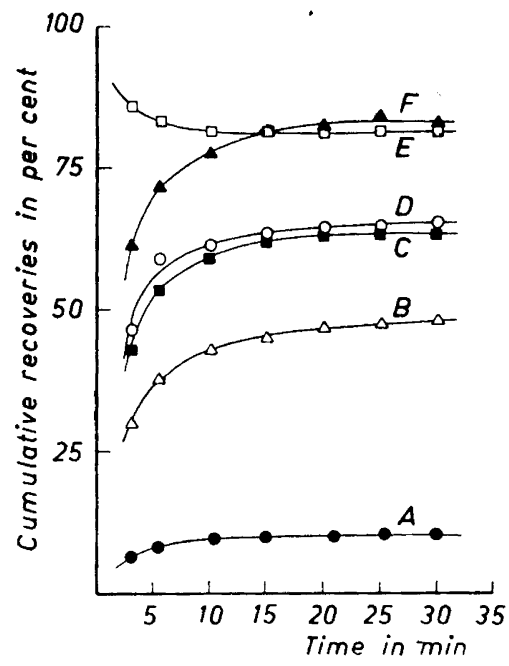

Fig. 3. Equilibrium between DMABF and Dowex $50 \mathrm{X} 1$ at varying concentrations of alcohol and hydrochloric acid.
A $0.05 \mathrm{~N}$ hydrochloric acid in $30 \%$ alcohol
B $0.05 \mathrm{~N}$ hydrochloric acid in $50 \%$ alcohol
C $0.05 \mathrm{~N}$ hydrochloric acid in $70 \%$ alcohol
D $0.05 \mathrm{~N}$ hydrochloric acid in $90 \%$ alcohol
E $0.1 \quad \mathrm{~N}$ hydrochloric acid in $70 \%$ alcohol
$\mathrm{F} \quad 0.1 \mathrm{~N}$ hydrochloric acid in $70 \%$ alcohol

ABCD and F: Dowex $50 \mathrm{Xl}$ with DMABF adsorbed was shaken with the corresponding acid.

E: Dowex $50 \mathrm{X} 1$ was shaken with DMABF dissolved in the corresponding acid.

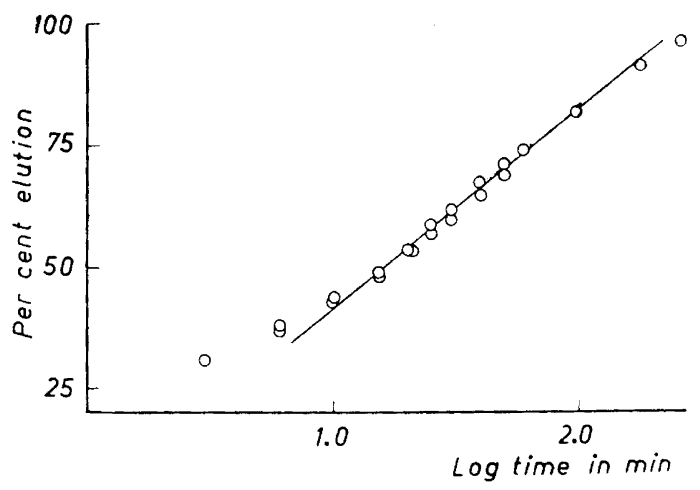

Fig. 4. Equilibrium between DMABF and Dowex $50 \mathrm{Xl}$ with $0.5 \mathrm{M}$ sodium bromide in $70 \%$ alcohol.

Acta Chem. Scand. 12 (1958) No. 7 
vely small, the benzethonium chloride contains a fairly long chain, and the DMABF is rather large. The long-chained benzethonium ion could not be completely adsorbed on ion exchangers with more than $4 \%$ crosslinking. On the ion exchangers $\mathrm{X} 12$ and $\mathrm{X} 16$ the adsorption from water was very small. Further, there is a tendency towards a slower elution of the amount adsorbed on the more crosslinked resins. For all crosslinkings tried both the small ethyl quinolinium ion and the large DMABF ion are completely adsorbed. The elution rate is, however, greatly decreased if the crosslinking is increased. Further, the large DMABF ion is more strongly retained than the smaller ethyl quinolinium ion. It is interesting to note that the elution rate of DMABF has a pronounced minimum at X8 where the rate is only about $40 \%$ of that of X1 and $60 \%$ of that of X12 and X16.

In Fig. 3 the influence of the concentrations of alcohol and acid is clearly demonstrated from experiments on the equilibrium between DMABF and Dowex $50 \mathrm{X} 1$. The equilibrium is rapidly attained with alcoholic hydrochloric acid. Therefore, the column experiments were most likely performed under equilibrium conditions. With $0.1 \mathrm{~N}$ hydrochloric acid in $70 \%$ alcohol the equilibrium was reached from both sides, thus showing that it is a true one. With $0.5 \mathrm{M}$ sodium bromide in $70 \%$ alcohol the process is much slower and here it is possible to apply Langmuir's adsorption isotherm. This is shown in Fig. 4, where the desorption is directly proportional to the logarithm of the time.

\section{EXPERIMENTAL}

\section{Colum n experiments}

The ion exchangers $(200-400$ mesh) used were washed with ammonium citrate solution to remove traces of heavy metals and were then alternately treated several times with aqueous and alcoholic solutions of sodium hydroxide and hydrochloric acid. By this treatment the blanks became negligible.

Unless otherwise stated Dowex $50 \mathrm{Xl}$ in the hydrogen form was used. The columns were $20-30 \times 4 \mathrm{~mm}$ and could adsorb 15 to $20 \mathrm{mg}$ of substance. When working with resins with a low degree of crosslinking the swelling and shrinking are often cumbersome but with the method used in this work no troubles were encountered. When changing solvents in the columns bubbles are easily formed. They can be avoided by using freshly boiled solvents. The flow rate was kept at about $1 \mathrm{ml} / \mathrm{min}$.

The reagents were of analytical grade and the compounds investigated were of the highest quality available and recrystallized from alcohol and water. Most of the quaternary compounds were synthetized by standard methods and recrystallized from alcohol and water. The equivalent weights and elementary analyses were in good agreement with theory.

For most of the substances a standard curve was drawn at the maximum characteristic for the compound in question in the ultraviolet region and the concentrations of the solutions assayed with its aid. The solvent was usually water or alcohol-water. If acetone was used at the elution it had to be evaporated and the residue dissolved in the appropriate solvent for the final assay. Benzethonium chloride was titrated according to Carkhuff and Boyd ${ }^{17}$ and hyoscine methylnitrate was determined either according to Berggren and Nordberg ${ }^{18}$ or colorimetrically using bromothymol blue ${ }^{19}$.

Procedure 1 to $2 \mathrm{mg}$ of the substance to be investigated - of benzethonium chloride, however, $10 \mathrm{mg}$ and of hyoscine methylnitrate $10-15 \mathrm{mg}$ - dissolved in $10 \mathrm{ml}$ of water or alcohol-water was allowed to flow through the column which was then washed three times with $5 \mathrm{ml}$ of the solvent. The liquids were collected and assayed. The substances on the column were eluted with different solutions, the eluates diluted to the appropriate volume, and assayed. Blanks were always run but their values were usually negligible. 
Equilibrium experiments

$50 \mathrm{ml}$ of Dowex $50 \mathrm{X} 1$ was mecanically stirred in $400 \mathrm{ml}$ of $50 \%$ alcohol and from a burette a solution of $207.4 \mathrm{mg}$ DMABF in $100 \mathrm{ml}$ of $50 \%$ alcohol was slowly added during $2 \mathrm{~h}$. The resin was transferred to a column and thoroughly washed with $50 \%$ alcohol and finally dried at $50^{\circ}$ over night. The resin so prepared contained $4.9 \%$ of moisture determined by the Karl Fischer method.

The resin was assayed by elution with $1 \mathrm{~N}$ perchloric acid in $70 \%$ alcohol. Three determinations gave 53.6, 53.1, and $53.9 \mathrm{mg}$ of DMABF per $\mathrm{g}$ of resin.

Prior to all experiments an accurately weighed amount, about $50 \mathrm{mg}$, of the resin was allowed to swell over night in $10.00 \mathrm{ml}$ of water. The rest of the elutriant, about $90.00 \mathrm{~g}$, was added and the mixture shaken. At known intervals $5.00 \mathrm{ml}$ was withdrawn in such a manner that no resin was removed and assayed spectrophotometrically. No special attempts were made to keep the temperature constant.

\section{REFERENCES}

1. Bregman, J. I. Ann. N.Y. Acad. Sci. 57 (1953) 125.

2. Büchi, J. and Furrer, F. Arzneimittel-Forsch. 3 (1953) 1.

3. Björling, C. O. and Berggren, A. J. Pharm. and Pharmacol. 5 (1953) 169, 615; Björling, C. O. and Berggren, A. Acta Chem. Scand. 9 (1955) 567.

4. Moore, S. and Stein, W. H. J. Biol. Chem. 211 (1954) 893.

5. Davey, C. L. Nature 179 (1957) 209.

6. Balenović, K. and Štefanac, Z. Chem. \& Ind. London 195623.

7. Jacobs, S., Work, T. S. and Kressman, T. R. E. Chem. \& Ind. London 1955117.

8. van Etten, C. H. Anal. Chem. 27 (1955) 954.

9. Kunin, R. and Myers, R. J. Discussions Faraday Soc. 7 (1949) 114.

10. Sjöström, E. and Nykänen, L. Suomen Kemistilehti B 29 (1956) 23.

11. Hale, D. K., Packham, D. I. and Pepper, K. W. J. Chem. Soc. 1953844.

12. Bodamer, G. W. and Kunin, R. Ind. Eng. Chem. 45 (1953) 2577.

13. Gemant, A. J. Inst. Petrol. 40 (1954) 50.

14. Drèze, A. and Reith, W. S. Biochem. J. 63 (1956) 21 P.

15. Rückert, H. and Samuelson, O. Acta Chem. Scand. 11 (1957) 303, 315.

16. Berggren A. and Björling, C. O. Acta Chem. Scand. 11 (1957) 179.

17. Carkhuff, E. D. and Boyd, W. F. J. Am. Pharm. Assoc. Sci. Ed. 43 (1954) 240.

18. Berggren, A. and Nordberg, M. Farm. Revy 51 (1952) 177.

19. Björling, C. O. and Berggren, A. To be published.

Received May 20, 1958. 